\section{(2) OPEN ACCESS}

\title{
Prevalence and determinants of genital Chlamydia trachomatis among school-going, sexually experienced adolescents in urban and rural Indigenous regions of Panama
}

\author{
Amanda Gabster (ㄷ) , 1,2 Philippe Mayaud (1) , ${ }^{2}$ Alma Ortiz, ${ }^{1}$ Jorge Castillo, ${ }^{1}$ \\ Omar Castillero, ${ }^{1}$ Alexander Martínez 지, ${ }^{1}$ Anyelini López, ${ }^{1}$ Betsy Aizprúa, \\ Sherly Pitano, ${ }^{1}$ Anet Murillo, ${ }^{1}$ Juan Miguel Pascale (i) ${ }^{3,4}$
}

'Departamento de Genómica y Proteómica, Gorgas Memorial Institute for Health Studies, Panama City, Panama ${ }^{2}$ Faculty of Infectious and Tropical Diseases, Department of Clinical Research, London School of Hygiene and Tropical Medicine, London, UK ${ }^{3}$ Dirección General, Gorgas Memorial Institute for Health Studies, Panama City, Panama ${ }^{4}$ Facultad de Medicina, Universidad de Panama, Panama City, Panama

\section{Correspondence to} Amanda Gabster, Genómica y Proteómica, Gorgas Memorial Institute for Health Studies, Calle 36 Este, Panama; agabster@gorgas.gob.pa

Received 12 December 2019 Revised 30 June 2020 Accepted 9 July 2020 Published Online First 28 August 2020

Check for updates

\section{(c) Author(s) (or their} employer(s)) 2021. Re-use permitted under CC BY-NC. No commercial re-use. See rights and permissions. Published by BMJ.

\begin{tabular}{l}
\hline To cite: Gabster A, \\
Mayaud P, Ortiz A, \\
et al. Sex Transm Infect \\
2021:97:304-311. \\
\hline
\end{tabular}

\section{ABSTRACT}

Objectives To determine the prevalence and risk factors of genital Chlamydia trachomatis (CT) among school-going sexually experienced male and female adolescents in Panama.

Methods We conducted two multisite cross-sectional studies using two-stage cluster sampling to select adolescents aged 14-19years attending urban public high schools (URB) in Panama City, San Miguelito, Colón and Panama Oeste from 2015 to 2018, and in the rural Indigenous Comarca Ngäbe-Buglé (CNB) from JulyNovember 2018. CT testing was performed by real-time PCR on urine samples. Random-effects logistic regression accounting for sample clustering was used to identify risk factors.

Results We enrolled 3166 participants (54.3\% females), median age 17 years (IQR: 15.9-18.1), with no difference by sex. Sexual experience was reported by 1954 (61.7\%) participants. Combined CT prevalence was $15.8 \%$ (95\% Cl: 14.2 to 17.4), with no significant differences by region (URB $=16.5 \%, 95 \% \mathrm{Cl}: 14.7 \%$ to $18.6 \%$; $\mathrm{CNB}=13.6 \%, 95 \% \mathrm{Cl}: 10.9 \%$ to $16.8 \%$; $\mathrm{p}=0.12$ ). In an age-and-region-adjusted analysis, CT prevalence was higher among female participants compared with males (21.6\% vs $9.1 \%$, adjusted OR $(A O R)=2.87,95 \% \mathrm{Cl}: 1.62$ to 5.10$)$. Among sexually experienced females, CT prevalence was higher among those who reported $\geq 3$ lifetime sex partners compared with one partner ( $33.5 \%$ vs $15.3 \%, A O R=2.20,95 \% \mathrm{Cl}$ : 1.09 to 4.07$)$; and among those reporting at least one pregnancy compared with nulligravidae participants (30.9\% vs $13.8 \%, A O R=1.89,95 \%$ Cl: 1.05 to 3.43 ). In unadjusted analyses among males, CT was associated with older age ( $11.5 \%$ among those aged $18-19$ years vs $3.4 \%$ among those aged $14-15$ years, $O R=3.69$, $95 \%$ Cl: 1.10 to 12.33$)$.

Conclusions We report high CT prevalence among sexually experienced, school-going adolescents in Panama. Female adolescents, particularly those with multiple sex partners and a history of pregnancy, were at highest risk. Adolescent-targeted CT screening should be implemented in Panama. Additionally, evidencebased comprehensive sexuality education will be imperative.

\section{INTRODUCTION}

Genital Chlamydia trachomatis (CT) infection is the most commonly reported bacterial STI in industrialised countries. ${ }^{1}$ The infection is more often observed in females than males. ${ }^{2}$ If left untreated, CT can lead to serious sequelae, that is, infertility, and ongoing transmission. ${ }^{3}$ Asymptomatic CT infection is found in approximately $70 \%$ of infected females and $50 \%$ of infected males. ${ }^{4}$

Among female adolescents, acquisition of CT has been associated with biological and behavioural factors. Cervical ectopy, common among female adolescents, increases columnar epithelium exposure which becomes more vulnerable to CT infection. Additionally, compared with older adolescents, younger adolescents typically have thinner vaginal mucus, which facilitates microorganism penetration into cells. ${ }^{2}$ In terms of psychosocial development, hormonal and cognitive changes occurring during adolescence lead to greater risk taking and less self-regulation. ${ }^{2}$ Despite the high prevalence of CT among adolescents, effective screening strategies for long-term reduction in CT are limited in this population. $^{5}$

In Panama, little STI research has been previously conducted among adolescent populations. The urban population in Panama is largely concentrated in the districts surrounding the canal area: Panama City, San Miguelito, Colón and Panamá Oeste (online supplementary map 1). Additionally, the largest population of Indigenous peoples live primarily in an administratively autonomous region in western Panama called the Comarca Ngäbe-Buglé (CNB) (online supplementary map 1). The CNB has had an increase in new HIV diagnoses since 2004, however, data on the prevalence of other STIs, such as CT, have been lacking. ${ }^{6}$ Panama uses syndromic management to diagnose and treat STIs, including genital CT, but there is currently no organised CT screening. ${ }^{7}$ Chlamydia is a reportable disease in Panama, but not considered of obligatory notification. The Ministry of Health (MOH) reportable and notifiable disease database shows that among young women aged 15-19 years, there is little information on CT (zero reported cases), with only 76 
cases of pelvic inflammatory disease (PID), a possible complication of untreated CT, for the whole country (unpublished database, $\mathrm{MOH}, 2014$ ).

The WHO Global STI Strategy emphasises the need to collect STI data stratified by age, sex and location and the identification of populations where STI transmission is most likely to occur, in order to plan and undertake targeted interventions. ${ }^{8}{ }^{9}$ The high school enrolment rate is relatively high across Panama (around $63 \%$ nationally, $56 \%$ across the study regions, unpublished data, Ministerio de Educación, 2015), allowing a relatively sound sampling frame to study the epidemiology of STIs among school going adolescents. From 2015 to 2018, we conducted a twostage random cluster sampling study among school-going adolescents aged 14-18 years in the urban district of Panama City and reported a CT prevalence of $21.4 \%$ overall $(30.9 \%$ in females, $6.2 \%$ in males). ${ }^{6}$ In 2018 , we conducted a second study with similar design among school-going adolescents aged 14-19 years in the rural Indigenous CNB and reported a prevalence of $13.1 \%$ overall $\left(17.5 \%\right.$ in females, $10.7 \%$ in males). ${ }^{10}$ Together these regions account for $48 \%$ of the estimated 300000 public schoolgoing adolescents in Panama (unpublished database, Ministerio de Educación, 2014). The present paper uses the combined data from the published studies in a new analysis aimed at examining for the first time the risk factors of genital CT infection among sexually experienced adolescents living in Panama with sufficient statistical power.

\section{METHODS}

We conducted two separate multisite cross-sectional studies in urban areas of Panama (ie, Panama City, San Miguelito, Colón, and Panamá Oeste, urban (URB) settings) during June-August 2015-2018 (one region per school year), and in rural Indigenous sites of CNB during July-November 2018 (one school year).

\section{Study design and populations}

The study population consisted of male and female adolescent students aged 14-19 years enrolled in high schools (10th-12th grades in URB, 7 th-12th grades in CNB). A two-stage cluster sample design with random sampling of clusters and equal probability of selection was used.

In URB, we included 24 of 29 public high schools, and 309 classrooms, randomly selected from 4 urban regions for a total sample size of 3166 students. In CNB, we included 10 of 20 eligible public high schools and 66 classrooms, for a total sample of 700 students, as reported. ${ }^{10}$ The sample sizes were calculated to determine an expected CT prevalence of $10 \%$ in URB, as found in a similar study in the region, and 20\% in CNB, with 5\% precision and an expected $55 \%-60 \%$ of adolescents reporting being sexually experienced and eligible for STI testing. ${ }^{611} 12$ Overall, we included 375 classrooms from a total sampling frame of 10 625 students (figure 1).

\section{Study procedures}

The detailed procedures of each study have been published. ${ }^{610}$ In brief, the guardians of minor students (aged 14-17 years) were invited to attend a study information meeting and asked to give consent for their minor child. Each eligible minor student was then asked for their informed assent into the study. Older students (aged 18-19 years) were asked to provide informed consent directly. Consenting adolescents were asked to selfcomplete a questionnaire on a tablet computer (URB: EpiInfo Companion for Android, CDC, Georgia, USA; CNB: Kobo Toolbox, Harvard Humanitarian Initiative, Massachusetts,
USA). The questionnaire was piloted in one high school each of URB and CNB for understanding and acceptability. Questions were not obligatory, and included participant age and ethnicity. Past sexual experience was ascertained through one or more positive responses to the following questions: Have you ever had: sex? vaginal sex? anal sex? oral sex? been forced to have sex? sex with a boy/man/woman/girl? used a condom during sex? Do you report more than zero sexual partners in your life?

All participants were asked to provide a blood sample for HIV and STI serologies (results reported elsewhere ${ }^{610}$ ) and a 20-40 mL first-void urine sample. Urine samples were tested for STIs by molecular assays among participants with disclosed sexual experience or those who had $\geq 1$ positive serological STI test (for HIV, syphilis, herpes or hepatitis B surface antigen), but responded no prior sexual experience.

Participants were given appointment cards to attend the nearest $\mathrm{MOH}$ health centre within 2-4 weeks to receive their test results, counselling, condoms and treatment. Defaulting participants were reminded several times by study team members and school counsellors to collect their results. Overall, $74 \%$ of participants needing treatment were treated, including HIV and syphilis seropositive participants.

\section{STI laboratory testing}

For the URB study, a multiplex real-time assay was used (Real-TM Sacace CT/Neisseria gonorrhoeae (NG)/Mycoplasma genitalium/Trichomonas vaginalis, Sacace Biotechnologies, Como, Italy). For the CNB study, the CT/NG Abbott Real-Time PCR was used (Abbott Laboratories, Abbott Park, USA). The Genomics Laboratory at the Instituto Conmemorativo Gorgas de Estudios de la Salud undertook all testing. The laboratory has been enrolled in regular External Quality Assessment (EQA) schemes since 2014 and has received a qualification of excellence on 11/11 completed evaluations. For CT, EQA was carried out through the College of American Pathologists; there was $100 \%$ result concordance with other laboratories.

\section{Statistical analyses}

For this analysis, we combined data from both studies and focused on results of participants who completed the questionnaire and gave a urine sample. The $\chi^{2}$ test was used to evaluate the difference in sexual behaviours between URB and CNB regions, and male and female participants. The Kruskal-Wallis test was used to evaluate significant differences in CT prevalence by region, age, participant sex and sexual behaviour. Missing data were excluded. Weighting of data was not necessary as sampling design used self-weighting and equal probability of selection. ${ }^{10}$ In a first analysis including all participants together, then in sex-segregated analyses, we used random-effects logistic regression to calculate unadjusted univariable ORs and their 95\% CIs. ${ }^{10}{ }^{13}$ Variables associated with the outcome of $\mathrm{CT}$ at $\mathrm{p}<0.2$ in univariable analyses were included in multivariable models. The multivariable models were adjusted for the a priori confounders of region, sex and age in the first model and in sex-specific models, adjusted by region and age. Distal (sociodemographic) then proximate (behavioural) variables were included. ${ }^{14}$ Variables independently associated with CT outcome at $\mathrm{p}<0.1$ were included in the final model to provide adjusted ORs (AORs) and their $95 \%$ CIs. 


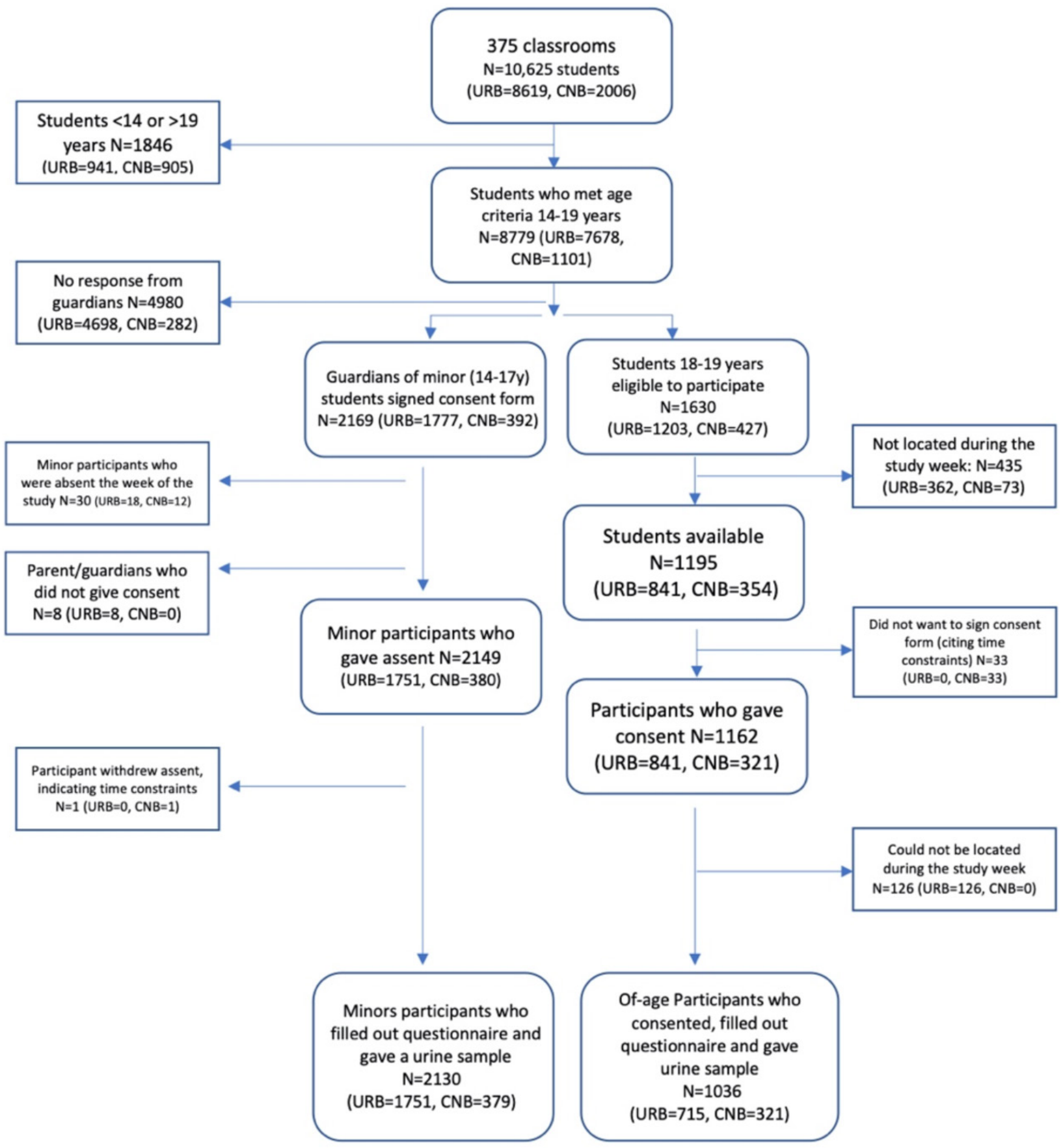

Figure 1 Sampling flow chart of participant inclusion in urban public high schools (URB) and the Indigenous rural, Comarca Ngäbe-Buglé regions (CNB) of Panama.

\section{Ethical issues}

Laboratory findings were provided back to participants, and any STIs (serological and genital) were treated at health clinics according to national guidelines.

\section{RESULTS}

A total of 10625 individuals were assessed for eligibility in URB and CNB schools, of whom 8779 were within the inclusion age range (14-19 years) (figure 1). Overall, 3166 participants were included (54.3\% females), with 2130 (67.3\%) minor participants aged 14-17 years (URB: 1751; CNB: 379) and $1036(32.7 \%)$ participants aged 18-19 years (URB: 715; CNB: 321) who responded to the questionnaire and provided a urine sample. Some urine samples did not have sufficient volume to undertake CT testing and participants could not be recontacted for a new sample (of sexually experienced participants, URB: $\mathrm{n}=9$, CNB: $\mathrm{n}=21$ ).

The median age of participants overall was 17 years (IQR: 15.9-18.1), with minor differences by site and gender (URB females: 17 years, IQR: 16-18; URB males: 17 years, IQR: 
Table 1 Characteristics of study participants in urban Panama (URB) and rural Comarca Ngäbe-Buglé (CNB) regions, Panama, 2015-2018

\begin{tabular}{|c|c|c|c|c|c|c|c|c|c|}
\hline \multicolumn{10}{|c|}{ Demographics-all participants $(n=3166)^{*}$} \\
\hline & \multicolumn{4}{|c|}{ URB $(n=2466 ; 77.9 \%)^{*}$} & \multicolumn{4}{|c|}{ CNB $(n=700 ; 22.1 \%)^{*}$} & \multirow{3}{*}{$\begin{array}{l}P \text { value between } \\
\text { regions (both } \\
\text { sexes) }\end{array}$} \\
\hline & Total & Females & Males & & Total & Females & Males & & \\
\hline & $\mathrm{n} / \mathrm{N}(\%)$ & $\mathrm{n} / \mathrm{N}(\%)$ & $\mathrm{n} / \mathrm{N}(\%)$ & $P$ value & $\mathrm{n} / \mathrm{N}(\%)$ & $\mathrm{n} / \mathrm{N}(\%)$ & $\mathrm{n} / \mathrm{N}(\%)$ & $P$ value & \\
\hline Region & 2466 & $1405 / 2466(57.0)$ & $1061 / 2466(43.0)$ & & 700 & $316 / 700(45.1)$ & $384 / 700(54.9)$ & & \\
\hline Age groups, years & & & & 0.35 & & & & $<0.01$ & $<0.01$ \\
\hline $14-15$ & $\begin{array}{l}397 / 2463 \\
(16.1)\end{array}$ & 233/1404 (16.6) & $164 / 1059(15.5)$ & & $157 / 700(22.4)$ & $88 / 316(27.9)$ & 88/384 (18.0) & & \\
\hline $16-17$ & $1351 / 2463(54.9)$ & $779 / 1404$ (55.5) & $572 / 1059(54.0)$ & & $200 / 700(31.7)$ & $113 / 316(17.1)$ & 109/384 (28.4) & & \\
\hline $18-19$ & $715 / 2463(29.0)$ & $392 / 1404$ (27.9) & $323 / 1059$ (30.4) & & $321 / 700$ (17.4) & $115 / 316(18.7)$ & $206 / 384(53.7)$ & & \\
\hline Ethnicity & & & & 0.97 & & & & 0.19 & $<0.01$ \\
\hline $\begin{array}{l}\text { Latino/mixed } \\
\text { Indigenous/African/ } \\
\text { Asian descent }\end{array}$ & $2242 / 2336(95.9)$ & $1279 / 1334(95.9)$ & $961 / 1002(95.9)$ & & $34 / 686(5.0)$ & $19 / 309(6.2)$ & $15 / 377(4.0)$ & & \\
\hline Indigenous only & $96 / 2336(4.1)$ & $55 / 1334(4.1)$ & $41 / 1002(4.1)$ & & $652 / 686(95.0)$ & $290 / 309(93.9)$ & $362 / 377(96.0)$ & & \\
\hline Reported ever had sex & & & & 0.37 & & & & 0.14 & $<0.01$ \\
\hline No & $1048 / 2466(42.5)$ & $608 / 1405(43.3)$ & $440 / 1061(41.5)$ & & $163 / 699(23.3)$ & $82 / 316(26.0)$ & $81 / 383(21.2)$ & & \\
\hline Yes & $1418 / 2466(57.5)$ & $797 / 1405$ (56.7) & $621 / 1061$ (58.5) & & $536 / 699(76.7)$ & $234 / 316(74.1)$ & $302 / 383(78.8)$ & & \\
\hline
\end{tabular}

Values in bold are significant at $p<0.05$.

*Denominators change in each category due to the total number of responses per question.

16-18; CNB females: 17 years, IQR: 14-19; CNB males: 18 years, IQR: 16-18). In URB sites, the majority of participants (95.9\%) were of Latino/mixed Latino or Indigenous or African or Asian descent, where $95.0 \%$ of CNB participants were of Indigenous ethnicity (table 1).

\section{Sexual behaviour}

There was a difference in reported sexual experience between the URB and CNB adolescents with $57.5 \%$ of URB participants and $76.7 \%$ of $\mathrm{CNB}$ school-going participants reporting prior sexual experience $(\mathrm{p}<0.01)$. There were no significant differences between sexes within either region (table 1). Of those who reported prior sexual activity, the median age at first sexual intercourse was similar in both regions (URB: 15 years, IQR: 14-16 years; CNB: 15 years, IQR: $14-16.5$ years). URB participants were more likely to report $\geq 3$ sexual partners in their lifetime $(46.5 \%$ vs $33.9 \%$ in $\mathrm{CNB}, \mathrm{p}<0.01)$ and to report to have been recently sexually active $(81.3 \%$ vs $43.0 \%$ in $\mathrm{CNB}$, $\mathrm{p}<0.01$ ), whereas CNB participants were more likely to report same-sex sex $(9.1 \%$ vs $3.6 \%, \mathrm{p}<0.01)$ and forced sex $(13.3 \%$ vs $8.3 \%, \mathrm{p}<0.01$ ) (table 2).

\section{Chlamydia trachomatis prevalence and risk factors}

Combining both regions and both sexes, 1924 participants were tested for CT (1409 in URB, 515 CNB). Of those, 303 tested positive (overall prevalence 15.8\%, 95\% CI: 14.2 to 17.4). There were no differences in CT prevalence by region (URB: 16.5\%, 95\% CI: 14.7 to 18.6 ; CNB: $13.6 \%$, 95\% CI: $10.9 \%$ to $16.8 \%)$. In the unadjusted univariable analyses, participants aged 18-19years had higher CT prevalence than participants aged $14-15$ years $(\mathrm{OR}=1.14,95 \% \mathrm{CI}$ : 1.02 to 1.28$)$. In the multivariable analyses, after adjusting for age and region, there was a significantly higher CT prevalence among female participants $(21.6 \%, 95 \% \mathrm{CI}: 19.2 \%$ to $24.2 \%)$ compared with males (9.1\%, 95\% CI: 7.4 to 11.1$)(\mathrm{AOR}=2.87,95 \% \mathrm{CI}: 1.62$ to 5.10$)$ (table 3, panel A).

Among female participants, in the unadjusted univariable analyses, associations with CT included: age $(\mathrm{OR}=1.14$, $95 \% \mathrm{CI}: 1.03$ to 1.99 ); $\geq 3$ reported lifetime sex partners lifetime $(\mathrm{OR}=2.82,95 \% \mathrm{CI}: 1.84$ to 4.32$)$ and having had $\geq 1$ pregnancies $(\mathrm{OR}=2.79,95 \% \mathrm{CI}: 1.72$ to 4.94$)$. In the multivariable, age-adjusted and region-adjusted analysis, CT was found to be associated with the report of $\geq 3$ lifetime sex partners compared with one partner $(33.5 \%$ vs $15.3 \%$; AOR $=2.20,95 \% \mathrm{CI}: 1.09$ to 4.07$)$, and experience of pregnancy $(30.9 \%$ vs $13.8 \%$ in nulligravidae; $\mathrm{AOR}=1.89,95 \% \mathrm{CI}$ : 1.05 to 3.43 )(table 3 , panel B).

Among male participants in the unadjusted univariable analyses, age was associated with CT. Older adolescents (aged 18-19years) were more likely than those aged $14-15$ years to test positive for CT (11.5\% vs 3.4\%, OR=3.69, 95\% CI: 1.10 to 12.33 ), and borderline associations were found for those who reported $\geq 3$ lifetime sexual partners $(11.6 \%$ vs $6.6 \%$ in those reporting one partner, $\mathrm{OR}=1.87,95 \% \mathrm{CI}$ : 0.92 to 3.75 ) and among those who reported to have impregnated a female $(18.9 \%$ vs $8.8 \%$ among those who never impregnated, $\mathrm{OR}=2.36,95 \% \mathrm{CI}: 0.96$ to 5.84$)$, although these associations did not persist in the age-and region-adjusted multivariable analysis (table 3, panel C).

\section{DISCUSSION}

This study has included over 3000 adolescents recruited from urban and rural (Indigenous) areas of Panama, and tested nearly two-thirds (1924) for genital CT. The sampling frame included nearly half of all school-going adolescents aged 14-19 years in Panama-a country with a relatively good high -school enrolment rate $(63 \%)$ - representing one of the largest studies of STIs ever conducted among adolescents in the Central American region. A total of $36.1 \%$ of those who met age criteria in selected classrooms participated in the study (figure 1). The study responds to the WHO call to obtain regional age-stratified and sex-stratified STI prevalence data to guide the development of data-driven, locally relevant interventions. ${ }^{9}$ Among sexually experienced, school-going adolescents, we found a high CT prevalence overall (15.8\%), significantly higher among females (21.6\%) than males (9.1\%), but with no difference between urban and rural Indigenous areas. These rates are higher than those reported in other regional surveys, ${ }^{12}$ particularly among female adolescents (range: $2.2 \%-11.6 \%) .{ }^{15-18}$

Factors associated with CT in this population accord with those found in the literature: female sex, multiple lifetime partners, increasing age and having experienced a pregnancy. 
Table 2 Reported sexual behaviours among female and male, school-going, sexually experienced adolescents in urban Panama (URB) and rural Indigenous (Comarca Ngäbe-Buglé (CNB)), Panama, 2015-2018

\begin{tabular}{|c|c|c|c|c|c|c|c|c|c|c|c|}
\hline \multicolumn{12}{|c|}{ Sexual behaviour-among sexually experienced participants $(n=1954)$} \\
\hline & \multicolumn{4}{|l|}{ URB $(\mathrm{N}=1429)^{*}$} & \multicolumn{4}{|c|}{ CNB $(n=536)^{*}$} & \multirow{3}{*}{$\begin{array}{l}\text { Difference } \\
\text { between } \\
\text { region } \\
\text { totals }\end{array}$} & \multirow{3}{*}{$\begin{array}{l}P \text { value } \\
\text { between } \\
\text { females } \\
\text { (both } \\
\text { regions) }\end{array}$} & \multirow{3}{*}{$\begin{array}{l}\mathrm{P} \text { value } \\
\text { between } \\
\text { males } \\
\text { (both } \\
\text { regions) }\end{array}$} \\
\hline & Total & Females & Males & & Total & Females & Males & & & & \\
\hline & $\begin{array}{l}n / N \\
(\%)\end{array}$ & $\begin{array}{l}n / N \\
(\%)\end{array}$ & $\begin{array}{l}\mathrm{n} / \mathrm{N} \\
(\%)\end{array}$ & P value & $\begin{array}{l}\mathrm{n} / \mathrm{N} \\
(\%)\end{array}$ & $\begin{array}{l}\mathrm{n} / \mathrm{N} \\
(\%)\end{array}$ & $\begin{array}{l}n / N \\
(\%)\end{array}$ & $P$ value & & & \\
\hline $\begin{array}{l}\text { Number of lifetime sexual } \\
\text { partners }\end{array}$ & & & & $<0.01$ & & & & 0.03 & $<0.01$ & $<0.01$ & $<0.01$ \\
\hline 1 & $318 / 1000(31.8)$ & $\begin{array}{l}217 / 582 \\
(37.3)\end{array}$ & $\begin{array}{l}101 / 418 \\
(24.2)\end{array}$ & & $\begin{array}{l}153 / 333 \\
(46.0)\end{array}$ & $\begin{array}{l}77 / 138 \\
(55.8)\end{array}$ & $76 / 195(39.0)$ & & & & \\
\hline 2 & $217 / 1000(21.7)$ & $\begin{array}{l}145 / 582 \\
(24.9)\end{array}$ & $\begin{array}{l}72 / 418 \\
(17.2)\end{array}$ & & $\begin{array}{l}67 / 333 \\
(20.1)\end{array}$ & $\begin{array}{l}28 / 138 \\
(20.3)\end{array}$ & $39 / 195(20.0)$ & & & & \\
\hline 3 or more & $465 / 1000(46.5)$ & $\begin{array}{l}220 / 582 \\
(37.8)\end{array}$ & $\begin{array}{l}245 / 418 \\
(58.6)\end{array}$ & & $\begin{array}{l}113 / 333 \\
(33.9)\end{array}$ & $\begin{array}{l}33 / 138 \\
(23.9)\end{array}$ & $80 / 195(41.0)$ & & & & \\
\hline $\begin{array}{l}\text { Recently sexually active } \\
\text { (sex in past month) }\end{array}$ & & & & $<0.01$ & & & & 0.89 & $<0.01$ & $<0.01$ & $<0.01$ \\
\hline No & 268/1429 (18.8) & $\begin{array}{l}126 / 802 \\
(15.7)\end{array}$ & $\begin{array}{l}142 / 627 \\
(22.7)\end{array}$ & & $\begin{array}{l}399 / 700 \\
(57.0)\end{array}$ & $\begin{array}{l}181 / 316 \\
(57.3)\end{array}$ & 218/384 (56.8) & & & & \\
\hline Yes & $1161 / 1429$ (81.3) & $\begin{array}{l}676 / 802 \\
(84.3)\end{array}$ & $\begin{array}{l}485 / 627 \\
(77.4)\end{array}$ & & $\begin{array}{l}301 / 700 \\
(43.0)\end{array}$ & $\begin{array}{l}135 / 316 \\
(42.7)\end{array}$ & $166 / 384(43.2)$ & & & & \\
\hline Condom use & & & & & & & & $<0.01$ & $<0.01$ & 0.56 & $<0.01$ \\
\hline Never or only sometimes & $834 / 1067(78.2)$ & $\begin{array}{l}501 / 626 \\
(80.0)\end{array}$ & $\begin{array}{l}333 / 441 \\
(75.5)\end{array}$ & 0.08 & $\begin{array}{l}295 / 312 \\
(94.6)\end{array}$ & $\begin{array}{l}119 / 133 \\
(89.5)\end{array}$ & $176 / 179(98.3)$ & & & & \\
\hline Always & 233/1067 (21.8) & $\begin{array}{l}125 / 626 \\
(20.0)\end{array}$ & $\begin{array}{l}108 / 441 \\
(24.5)\end{array}$ & & $\begin{array}{l}17 / 312 \\
(5.5)\end{array}$ & $\begin{array}{l}14 / 133 \\
(10.5)\end{array}$ & $3 / 179(1.7)$ & & & & \\
\hline Same-sex sex & & & & 0.02 & & & & 0.09 & $<0.01$ & $<0.01$ & $<0.01$ \\
\hline No & 1163/1206 (96.4) & $\begin{array}{l}671 / 688 \\
(97.5)\end{array}$ & $\begin{array}{l}492 / 518 \\
(95.0)\end{array}$ & & $\begin{array}{l}359 / 395 \\
(90.9)\end{array}$ & $\begin{array}{l}152 / 162 \\
(93.8)\end{array}$ & 207/233 (88.8) & & & & \\
\hline Yes & $\begin{array}{l}43 / 1206 \\
(3.6)\end{array}$ & $\begin{array}{l}17 / 688 \\
(2.5)\end{array}$ & $\begin{array}{l}26 / 518 \\
(5.0)\end{array}$ & & $\begin{array}{l}36 / 395 \\
(9.1)\end{array}$ & $\begin{array}{l}10 / 162 \\
(6.2)\end{array}$ & $26 / 233(11.2)$ & & & & \\
\hline Forced sex & & & & 0.38 & & & & 0.40 & $<0.01$ & $<0.01$ & $<0.01$ \\
\hline Never & $1233 / 1344(91.7)$ & $\begin{array}{l}698 / 756 \\
(92.3)\end{array}$ & $\begin{array}{l}535 / 588 \\
(91.0)\end{array}$ & & $\begin{array}{l}572 / 660 \\
(86.7)\end{array}$ & $\begin{array}{l}252 / 295 \\
(85.4)\end{array}$ & $320 / 365(87.7)$ & & & & \\
\hline One or more times & $\begin{array}{l}111 / 1344 \\
(8.3)\end{array}$ & $\begin{array}{l}58 / 756 \\
(7.7)\end{array}$ & $\begin{array}{l}53 / 588 \\
(9.0)\end{array}$ & & $\begin{array}{l}88 / 660 \\
(13.3)\end{array}$ & $\begin{array}{l}43 / 295 \\
(14.6)\end{array}$ & $45 / 365(12.3)$ & & & & \\
\hline $\begin{array}{l}\text { Been pregnant (females) } \\
\text { or impregnated partner } \\
\text { (males) }\end{array}$ & & & & $<0.01$ & & & & $<0.01$ & $<0.01$ & $<0.01$ & $<0.01$ \\
\hline Nulligravidae & 1309/1445 (90.6) & $\begin{array}{l}347 / 441 \\
(78.7)\end{array}$ & $\begin{array}{l}962 / 1004 \\
(95.8)\end{array}$ & & $\begin{array}{l}648 / 683 \\
(94.9)\end{array}$ & $\begin{array}{l}264 / 299 \\
(88.3)\end{array}$ & $384 / 384(100.0)$ & & & & \\
\hline 1 or more pregnancies & $\begin{array}{l}136 / 1445 \\
(9.4)\end{array}$ & $\begin{array}{l}94 / 441 \\
(21.3)\end{array}$ & $\begin{array}{l}42 / 1004 \\
(4.2)\end{array}$ & & $\begin{array}{l}35 / 683 \\
(5.1)\end{array}$ & $\begin{array}{l}35 / 299 \\
(11.7)\end{array}$ & $0 / 384(0.0)$ & & & & \\
\hline
\end{tabular}

Values in bold are significant at $\mathrm{P}<0.05$

*Denominators change in each category due to the total number of responses per question.

Worldwide, female adolescents are more likely than males to acquire CT infection due to cervical ectopy. ${ }^{2}$ Transmission of STIs is more effective from males to females than vice versa, which may also be due to tissue trauma and exposure to a large volume of semen (compared with female genital secretions for male exposure) over a greater mucosal area. ${ }^{19}$ Non-biological factors also account for increased CT prevalence among females, such as socioeconomic, cultural and gender norms. ${ }^{2}$

For female adolescents, and marginally for males, the risk of genital CT was related to having had three or more sexual partners, which accord to a vast body of research linking numbers of sexual partners and increased STI risk. Genital CT has an infectious period ranging from months to years. Transmission of CT is sustained by concurrent partnerships, short gaps between sexual partners and sexual partners from different sexual networks. ${ }^{2}$

We found the experience of pregnancy to be a significant risk factor for CT among female participants, reflecting similar findings in international and regional studies. ${ }^{20}$ Sexual behaviour factors (higher number of sexual partners, younger age at sex initiation, more frequent coitus, as well as low condom use before and during pregnancy) are likely to contribute to such association. However, changes in the immune and cervical mucosal environment during pregnancy may also explain an increased susceptibility to STIs. ${ }^{21}$ In this study, we were unable to determine the precise role of these individual factors, as female participants who had experienced pregnancy were not less likely to report condom use. However, our findings suggest that antenatal clinics may provide an excellent opportunity for CT screening for adolescent females. An economic analysis in the high-income country of Australia, found that CT screening among pregnant women aged 16-25 years would be cost-effective, when overall CT prevalence in the target population was estimated to be over $11 \% .^{22}$

Universal opt-out CT screening programmes among adolescent and young adult populations have been shown to be successful. School-based opt-out screening in an urban setting in the USA, found a significant reduction in CT prevalence from $10.2 \%$ to $6.3 \%$ in 5 years. ${ }^{23}$ A recent systematic review of modelling 


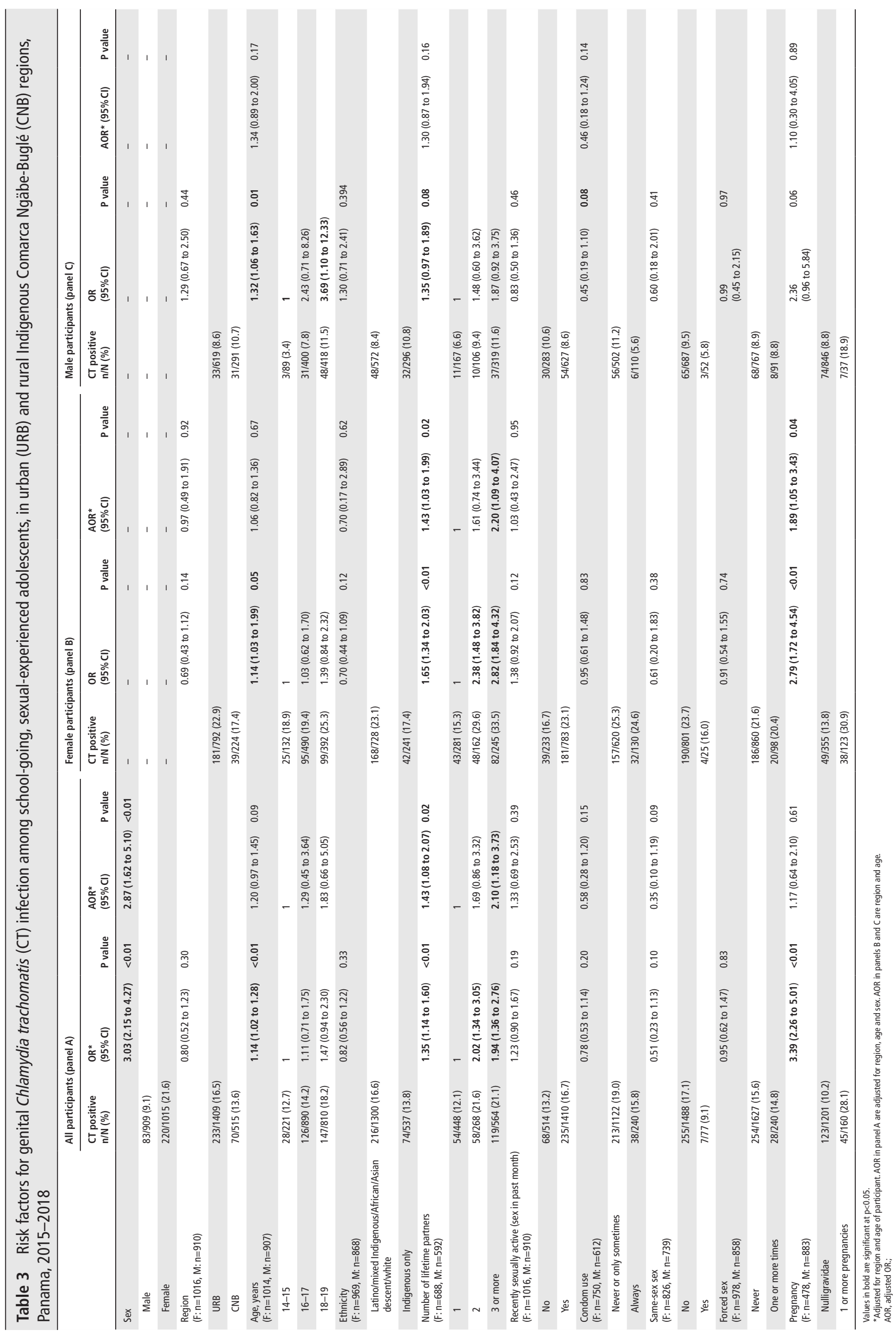


studies found that CT screening every $2-5$ years among young people could reduce $\mathrm{CT}$ prevalence in the population after $5-10$ years. ${ }^{24}$ Additionally, universal screening has been shown to be cost-effective in US family planning clinic settings for young adults, where the estimated CT prevalence was over $2 \%,{ }^{25}$ and among all young females in other US settings. ${ }^{26}$ Opt-out testing has been found to decrease the overall CT prevalence by 55\% among young women in the USA, when compared with the use of a risk-based screening strategy. ${ }^{27} \mathrm{By}$ contrast, epidemiological studies show that in the UK a reduction in population-level CT prevalence may not be occurring, as mathematical models would have predicted. ${ }^{28}$

Panama relies on syndromic management of STIs, ${ }^{7}$ which is unlikely to bring a high asymptomatic CT prevalence under control. ${ }^{8}$ The low number of reported PID and CT cases in this age group contrasts with the high CT prevalence found in the study, which could be explained by a combination of lack of suspicion among healthcare professionals and testing facilities in the country and the asymptomatic nature of CT. Our results highlight the need to adopt a more proactive approach, such as targeted screening programmes within the adolescent population to curb CT prevalence and incidence. ${ }^{9}$ Additionally, preventative educational programmes and comprehensive sexuality education should be developed in Panama to include awareness about HIV and STIs, and should be implemented in public schools where these are currently virtually non-existent.

Our study had a number of strengths. First, we were able to include a large sample size from a sampling frame of almost half of school-going adolescents in the country, which resulted in a robust and precise estimate of CT prevalence in this population. Second, this estimate was obtained using sensitive molecular diagnostics backed by strong EQA results. Third, we used a self-applied electronic data-capture to mitigate reporting bias that often appears with questionnaires that investigate sensitive sexual behaviour. Furthermore, our tools were piloted and validated in both URB and CNB sites. ${ }^{6}{ }^{10}$ This study also had limitations. First, we may have underestimated CT prevalence, as most at-risk adolescents may not attend school, or their guardian(s) may not have attended the prestudy meetings or given consent to participate. Second, we did not extend CT testing to the entire study population. Participants who reported no sexual activity were not tested, unless they had positive HIV/STI serological results (this added only $10 \mathrm{HSV}$-2-seropostive adolescents in $\mathrm{CNB}$ and 11 in URB). Third, the two surveys were conducted 3 years apart in time and did not use the same molecular assays, which may have introduced measurement biases that we cannot quantify, although we employed well-validated EQA-backed up assays. Fourth, our estimates were biased towards the URB sites

\section{Key messages}

- There is a high burden of genital Chlamydia trachomatis infection among school-going urban and rural Indigenous adolescents in Panama.

- Adolescent females, especially those who have experienced pregnancy are most affected.

- Panama currently uses syndromic management for STI diagnosis, however there is a need for targeted chlamydia screening, diagnosis and treatment interventions, especially among sexually-experienced adolescents and during prenatal visits. Additionally, introduction of evidence-based comprehensive sexuality education will be crucial. with the largest number of participants. Fifth, despite our careful developmental approach, we may have encountered reporting bias in sexual behaviour disclosure, as questionnaires were selfadministered. Finally, despite its large size and the combining of datasets, our study may have been under-powered to explore CT determinants in male participants who had lower prevalence.

In conclusion, we have provided robust age-stratified and sexstratified population-based data in order to estimate the burden of genital CT among school-going adolescents in Panama. We found high CT prevalence across urban and rural regions, indicating the need for prompt development of control interventions such as comprehensive sexuality education in schools and targeted CT screening, diagnosis and treatment within prenatal visits and among sexually experienced adolescents in schools, health centres or communities.

\section{Handling editor Catherine $\mathrm{H}$ Mercer}

Acknowledgements We are grateful to participants, their guardians, school administration, Ministry of Health and Ministry of Education for their support throughout the years of this study. We are also grateful to our field and laboratory teams at the Instituto Conmemorativo Gorgas de Estudios de la Salud, especially José Dyamond and Yaharelis Coronado. We would also like to the University of South Florida Medical School students who helped with sample collection during 2017 and 2018: Nisha Sunku, Indira Ranaweera, Emily Shipley, Elizabeth Lafranchise, and Marisol Caballero. Additionally, we are hugely appreciative of our other volunteers who helped with sample collection and post-test education: Sofia Sacco, Gonzalo Cabezas Talavero, University of Panama Medical Technology students, and 2018 Peace Corps Volunteers in the Comarca Ngäbe-Buglé, Panama. Dr Juan Miguel Pascale and Alexander Martinez are distinguished members of the National Research System that is supported by the National Secretariat of Science, Technology and Innovation.

Contributors AG and JMP designed and coordinated the URB study. AG and PM designed the CNB study. AO, JC, OC, AM performed laboratory analysis of chlamydia. AG and PM performed statistical analyses and interpretation. AL, BA, SP and AM aided in data collection. JMP oversaw data collection, analysis and manuscript creation. AG and PM wrote the first draft of the manuscript. All coauthors critically reviewed and approved the final manuscript draft.

Funding Panama's Ministerio de Economia y Finanzas and Panamás National STI/ HIV/Viral Hepatitis Program.

\section{Competing interests None declared.}

\section{Patient consent for publication Not required.}

Ethics approval We obtained approval for both studies from the national and regional Ministry of Education and school administration. The URB study was approved by the Comité de Bioética del Instituto Conmemorativo Gorgas (N701/CBI/ ICGES/15). The CNB study was approved by the Comité Nacional de Bioética (ECCNBI-2016-05-25, November 2017), and the London School of Hygiene and Tropical Medicine IRB (Ref: 14558, January 2018).

Provenance and peer review Not commissioned; externally peer reviewed.

Data availability statement Data may be obtained from a third party and are not publicly available. Data include indirect identifiers therefore for ethical reasons, are not in a repository.

Open access This is an open access article distributed in accordance with the Creative Commons Attribution Non Commercial (CC BY-NC 4.0) license, which permits others to distribute, remix, adapt, build upon this work non-commercially, and license their derivative works on different terms, provided the original work is properly cited, appropriate credit is given, any changes made indicated, and the use is non-commercial. See: http://creativecommons.org/licenses/by-nc/4.0/.

\section{ORCID iDs}

Amanda Gabster http://orcid.org/0000-0002-7712-0444

Philippe Mayaud http://orcid.org/0000-0001-5730947X

Alexander Martínez http://orcid.org/0000-0002-7816-3040

Juan Miguel Pascale http://orcid.org/0000-0003-3258-1359

\section{REFERENCES}

1 World Health Organization. Who guidelines for the treatment of Chlamydia trachomatis, 2016. Available: https://apps.who.int/iris/bitstream/handle/10665 246165/9789241549 714-eng.pdf? sequence=1 [Accessed Jul 2019].

2 Holmes KK, Sparling PF, Stamm WE, et al. Adolescents and STDs including HIV infection. Sexually transmitted diseases: McGraw HIII Medical, 2008: 165-86. 
3 Singh SK. Diagnostics to Pathogenomics of sexually transmitted infections. John Wiley \& Sons Ltd, 2019: 135-66.

4 Torrone $\mathrm{E}$, Papp J, Weinstock $\mathrm{H}$, et al. Prevalence of Chlamydia trachomatis genital infection among persons aged 14-39 years--United States, 2007-2012. MMWR Morb Mortal Wkly Rep 2014;63:834-8.

5 Low N, Bender N, Nartey L, et al. Effectiveness of Chlamydia screening: systematic review. Int J Epidemiol 2009;38:435-48.

6 Gabster A, Mohammed DY, Arteaga GB, et al. Correlates of sexually transmitted infections among adolescents attending public high schools, Panama, 2015. PLoS One 2016;11:e0163391.

7 Ministerio de Salud, Caja de Seguro Social, Instituto Conmemorativo Gorgas de Estudios de Salud. Normativa Nacional para El Abordaje integral de las Infecciones de Transmisión sexual en Panamá, Panamá 2014.

8 Vallely LM, Toliman P, Ryan C, et al. Performance of syndromic management for the detection and treatment of genital Chlamydia trachomatis, Neisseria gonorrhoeae and Trichomonas vaginalis among women attending antenatal, well woman and sexual health clinics in Papua New Guinea: a cross-sectional study. BMJ Open 2017;7:e018630.

9 World Health Organization. Global health sector strategy on sexually transmitted infections 2016-2021, 2016. Available: https://www.who.int/reproductivehealth/ publications/rtis/ghss-stis/en/ [Accessed Apr 2019].

10 Gabster A, Pascale JM, Cislaghi B, et al. High prevalence of sexually transmitted infections, and high-risk sexual behaviors among Indigenous adolescents of the Comarca Ngäbe-Buglé, Panama. Sex Transm Dis 2019;46:780-7.

11 De León RG, García LM, Chu EE, et al. Encuesta Nacional de Salud sexual Y Reproductiva. Instituto Conmemorativo Gorgas de Estudios de la Salud 2011.

12 Gutierrez J-P, Bertozzi SM, Conde-Glez CJ, et al. Risk behaviors of 15-21 year olds in Mexico lead to a high prevalence of sexually transmitted infections: results of a survey in disadvantaged urban areas. BMC Public Health 2006;6:49.

13 Bottomley C, Kirby MJ, Lindsay SW, et al. Can the buck always be passed to the highest level of clustering? BMC Med Res Methodol 2016;16:29.

14 Victora CG, Huttly SR, Fuchs SC, et al. The role of conceptual frameworks in epidemiological analysis: a hierarchical approach. Int J Epidemiol 1997;26:224-7.

15 Huneeus A, Schilling A, Fernandez MI. Prevalence of Chlamydia trachomatis, Neisseria gonorrhoeae, and Trichomonas vaginalis infection in Chilean adolescents and young adults. J Pediatr Adolesc Gynecol 2018;31:411-5.
16 Acevedo T, Stella L, López IM. Determinantes de salud sexual E its en adolescentes rurales, escolarizados, Medellín, Colombia, 2008. Medellín: Alcaldía de Medellín, 2011: 5. 7-24.

17 Rowley J, Vander Hoorn S, Korenromp E, et al. Chlamydia, gonorrhoea, trichomoniasis and syphilis: global prevalence and incidence estimates, 2016. Bull World Health Organ 2019;97:548-62.

18 Paredes MC, Gómez YM, Torres AM, et al. [Prevalence of infections by Chlamydia trachomatis and Neisseria gonorrhoeae among high school students in the Sabana Central area of Cundinamarca, Colombia]. Biomedica 2015;35:314-24.

19 Wong T, Singh A, Mann J, et al. Gender differences in bacterial STIs in Canada. BMC Womens Health 2004;4:S26.

20 Centers for Disease Control and Prevention. Sexually transmitted disease surveillance 2017 Chlamydia, 2017. Available: https://www.cdc.gov/std/stats17/chlamydia.htm [Accessed cited 2019 August].

21 Teasdale CA, Abrams EJ, Chiasson MA, et al. Incidence of sexually transmitted infections during pregnancy. PLoS One 2018;13:e0197696.

22 Ong JJ, Chen M, Hocking J, et al. Chlamydia screening for pregnant women aged $16-25$ years attending an antenatal service: a cost-effectiveness study. BJOG 2016;123:1194-202.

23 Dunville R, Peterson A, Liddon N, et al. Sustained reduction in Chlamydia infections following a school-based screening: Detroit, 2010-2015. Am J Public Health 2018;108:231-3.

24 Rönn MM, Wolf EE, Chesson $\mathrm{H}$, et al. The use of mathematical models of Chlamydia transmission to address public health policy questions: a systematic review. Sex Transm Dis 2017:44:278-83.

25 Marrazzo JM, Celum CL, Hillis SD, et al. Performance and cost-effectiveness of selective screening criteria for Chlamydia trachomatis infection in women. Implications for a national Chlamydia control strategy. Sex Transm Dis 1997;24:131-41.

26 Kraut-Becher JR, Gift TL, Haddix AC, et al. Cost-Effectiveness of universal screening for Chlamydia and gonorrhea in US jails. J Urban Health 2004;81:453-71.

27 Owusu-Edusei K, Hoover KW, Gift TL. Cost-Effectiveness of Opt-Out Chlamydia testing for high-risk young women in the U.S. Am J Prev Med 2016;51:216-24.

28 Smid J, Althaus CL, Low N. Discrepancies between observed data and predictions from mathematical modelling of the impact of screening interventions on Chlamydia trachomatis prevalence. Sci Rep 2019;9:7547. 